\title{
Integrated weed management: Tools and strategies in a world of pesticide restriction
}

\author{
Vittoria Giannini, ${ }^{1}$ Donato Loddo, ${ }^{2}$ J. Scott McElroy ${ }^{3}$ \\ ${ }^{1}$ Department of Agricultural Sciences, University of Sassari, Sassari, Italy; ${ }^{2}$ Institute for Sustainable Plant \\ Protection, National Research Council of Italy, Legnaro (PD), Italy; ${ }^{3}$ Department of Crop, Soil, and \\ Environmental Sciences, Auburn University, Auburn, AL, USA
}

Sustainable weed management requires an effective understanding of the biology of weed species and the possible impacts of practices on changes in weed community and individual weed species evolution. Herbicides have been the dominant tool for weed management in agricultural crops, horticulture, and amenity turfgrass. Because of the selection pressure exerted by herbicide use due to their incredible effectiveness, weed species communities changed to more tolerant species, and individual species evolved to resist herbicide modes of action. Sustainable weed management must take a lesson from the impacts of herbicides on weed communities and species. Future strategies must be more dynamic and integrated, creating instability in weed communities and increasing the number and diversity of practices affecting weeds. This special issue of the Italian Journal of Agronomy, entitled 'Integrated Weed Management: Tools and Strategies in a World of Pesticide Restriction,' collects 11 articles presenting innovative ideas and research to foster increased sustainable management practices.

In particular, five articles focused on the importance of the cover crop choice and practices to better manage weeds. For example, Boselli et al. (2021) tested eight cereal rye varieties as cover crops, focusing on their biomass production and allelochemical activities. They observed relevant differences in the weed suppression potential of the tested varieties and identified the most promising in terms of allelochemicals and biomass production.

Abou Chehade et al. (2021) tested, both in lab and field conditions, the allelopathic potential of two cover crops (rye and squarrose clover), used alone or in a mixture, on seed germination and growth of three arable weeds. They observed that the mixture of cover crops suppressed weeds more than the single species. These results agreed with Fogliatto et al. (2021), who found that the green mulching of a mixture of cover crops (hairy vetch +

Correspondence: Vittoria Giannini, Department of Agricultural Sciences, University of Sassari, viale Italia 39A, 07100 Sassari, Italy. E-mail: vgiannini@uniss.it

Received for publication: 29 September 2021.

Revision received: 10 October 2021.

Accepted for publication: 10 October 2021.

(C) Copyright: the Author(s), 2021

Licensee PAGEPress, Italy

Italian Journal of Agronomy 2021; 16:1981

doi:10.4081/ija.2021.1981

This article is distributed under the terms of the Creative Commons Attribution Noncommercial License (by-nc 4.0) which permits any noncommercial use, distribution, and reproduction in any medium, provided the original author(s) and source are credited.
Italian ryegrass) was more effective than the single species on weed control in rice fields. The promising effect of cover crops and green mulch for weed control was supported by the lab studies of Puig et al. (2021), evaluating the potential phytotoxic effect of 12 aqueous extracts from selected species and then postulating some allelochemicals as responsible for the herbicidal activity. Sias et al. (2021), in their review, investigated the cover crops in a soil-down perspective, that is focusing on how the modifications caused by cover crops on soil environmental conditions can be used to reduce weed pressure above-ground, decreasing seed survival, keeping seed dormancy, or/and reducing germination cues.

Four other articles focused on the reliance on recent technological advancements in the mechanical, digital and robotic sectors to improve weed management in fields. Nikolic et al. (2021) investigated the joining of time-specific and site-specific weed control through the combination of UAVs and the predictive model for weed emergence 'AlertInf', highlighting the effectiveness both in terms of weed control and reduction of herbicide use in a maize field study. The role of the seedling emergence model in optimizing the timing of herbicide application, thus increasing their efficacy, is also the topic of the research conducted in maize and soybean fields in Argentina by Picapietra and Acciaresi (2021). Nangle et al. (2021) tested different spray nozzles and ranges of spray droplets for crabgrass control with quinclorac in turfgrasses to optimize the quantity of distributed herbicide to the weed density and avoid off-site drift. Finally, Cutulle and Maja (2021) opened the perspective on robotic weeders introducing the Clearpath robotics platform Husky, providing cheap and autonomous weed control in small, diversified specialty crop farms.

The Special Issue also includes two reviews on more wide perspectives related to weed management. Gamble and Price (2021) proposed a new perspective on the relationship between soil tillage and weed management, showing strategies able to cope with the requirements for soil fertility conservation and, at the same time, judiciously use tillage as an element for managing resistant and troublesome weed species. Loddo et al. (2021) offered an exhaustive overview of the different strategies and tools that, if properly integrated, could help to lessen the current overreliance on herbicides for weed control while preserving the effectiveness of the chemical and transgenic technology for the future.

The research articles and reviews presented herein highlight beneficial research for increasing the sustainability of weed management strategies and have synthesized the current state of weed science in several areas. We are hopeful that this Special Issue will be of benefit to the international weed science community. 


\section{References}

Abou Chehade L, Puig CG, Souto C, Antichi D, Mazzoncini M, Pedrol N, 2021. Rye (Secale cereale L.) and squarrose clover (Trifolium squarrosum L.) cover crops can increase their allelopathic potential for weed control when used mixed as dead mulch. Ital. J. Agron. 16:1869.

Boselli R, Anders N, Fiorini A, Ganimede C, Faccini N, Marocco A, Schulz M, Tabaglio V, 2021. Improving weed control in sustainable agro-ecosystems: role of cultivar and termination timing of rye cover crop. Ital. J. Agron. 16:1807.

Cutulle MA, Maja JM, 2021. Determining the utility of an unmanned ground vehicle for weed control in specialty crop systems. Ital. J. Agron. 16:1865.

Fogliatto S, Patrucco L, De Palo F, Moretti B, Milan M, Vidotto F, 2021. Cover crops as green mulching for weed management in rice. Ital. J. Agron. 16:1850.

Gamble AV, Price AJ, 2021. The intersection of integrated pest management and soil quality in the resistant weed era. Ital. J. Agron. 16:1875.
Loddo D, McElroy JS, Giannini V, 2021. Problems and perspectives in weed management. Ital. J. Agron. 16:1854.

Nangle E, Raudenbush Z, Morris T, Fidanza M, 2021. Spray nozzle selection contributes to improved postemergence herbicide crabgrass control in turfgrass. Ital. J. Agron. 16:1846.

Nikolić N, Rizzo D, Marraccini E, Gotor AA, Mattivi P, Saulet P, Persichetti A, Masin R, 2021. Site and time-specific early weed control is able to reduce herbicide use in maize-a case study. Ital. J. Agron. 16:1780.

Picapietra G, Acciaresi HA, 2021. Junglerice (Echinochloa colona L.) seedling emergence model as a tool to optimize pre-emergent herbicide application. Ital. J. Agron. 16:1845.

Puig CG, Valencia-Gredilla F, Pardo-Muras M, Souto XC, Recasens J, Pedrol N, 2021. Predictive phytotoxic value of water-soluble allelochemicals in plant extracts for choosing a cover crop or mulch for specific weed control. Ital. J. Agron. $16: 1872$.

Sias C, Wolters BR, Reiter MS, Flessner ML, 2021. Cover crops as a weed seed bank management tool: a soil down review. Ital. J. Agron. 16:1852. 